Supporting information for:

\title{
Thiaborane Icosahedral Barrier Increased by the Functionalization of all Terminal Hydrogens in closo-1-SB ${ }_{11} \mathrm{H}_{11}$
}

Mario Bakardjiev, ${ }^{\dagger}$ Josef Holub, ${ }^{\dagger}$ Dmytro Bavol, ${ }^{\dagger}$ Jan Vrána, ${ }^{\S}$ Maksim A. Samsonov, ${ }^{\S}$ Aleš

Růžička, ${ }^{\S}$ Zdeňka Růžičková, ${ }^{\S}$ Jindřich Fanfrlík, ${ }^{\ddagger}$ and Drahomír Hnyk*,†

†Institute of Inorganic Chemistry of the Czech Academy of Sciences, 25068 Husinec - ̌̌ež, Czech Republic

${ }^{\S}$ Department of General and Inorganic Chemistry, Faculty of Chemical Technology, University of Pardubice, Studentská 573, 53210 Pardubice, Czech Republic

Institute of Organic Chemistry and Biochemistry of the Czech Academy of Sciences, Flemingovo nám. 2, 16610 Praha 6, Czech Republic 


\section{Syntheses and NMR Spectroscopy}

The starting material, closo-1- $\mathrm{SB}_{11} \mathrm{H}_{11}$, was prepared using a procedure described in the literature. ${ }^{1}$ Its solution $(0.5 \mathrm{~g}, 3 \mathrm{mmol})$ in $\mathrm{CH}_{3} \mathrm{I}(16.1 \mathrm{~g}, 112 \mathrm{mmol})$ was treated with anhydrous $\mathrm{AlCl}_{3}$ (6.0 g, $45 \mathrm{mmol}$, reagent grade, 98\%, Sigma-Aldrich), which was loaded into the reaction mixture in a glove box under nitrogen atmosphere. Subsequently, the mixture was heated in an oil bath to $250^{\circ} \mathrm{C}$ for 120 hours in a thick-walled reaction vessel equipped with a Teflon screw cap (see Figure S1). After cooling to ambient temperature, the reaction mixture was evaporated to dryness by a stream of nitrogen gas and then dissolved in hexane. After column chromatography on silica gel using hexane as an eluent, $1.2 \mathrm{~g}$ (ca $72 \%$ yield based on the starting closo-1-SB ${ }_{11} \mathrm{H}_{11}$ ) of 7,12- $\mathrm{I}_{2}-2,3,4,5,6,8,9,10,11-\mathrm{Me}_{9}$-closo-1-SB 11 (contaminated with 7,8,12- $\mathrm{I}_{3}-2,3,4,5,6,9,10,11-\left(\mathrm{CH}_{3}\right)_{8}$-closo-1-SB 11 as mentioned in the main text) was obtained as a white powder. No reaction was observed when $0.1 \mathrm{~g}$ of such a contaminated 1 was heated up to $400^{\circ} \mathrm{C}$ in neat trimethylaluminum $(2 \mathrm{~mL})$ in a sealed tube for 24 hours. As to the dismantling reactions, a solution of closo-1- $\mathrm{SB}_{11} \mathrm{H}_{11}(0.1 \mathrm{~g}, 0.62$ mmol) in $5 \mathrm{~mL}$ of hexane was stirred with $2 \mathrm{~mL}$ of a $25 \mathrm{wt}$. \% solution of $\left(\mathrm{CH}_{3}\right)_{4} \mathrm{NOH}$ in water for 1 hour, yielding a white precipitate of $\left.\left[7-\mathrm{SB}_{10} \mathrm{H}_{11}\right]^{-}\left[\mathrm{CH}_{3}\right)_{4} \mathrm{~N}\right]^{+}$. It was filtered off, washed with water and hexane and dried in vacuo ( $0.12 \mathrm{~g}, 87 \%$ yield). In contrast, when the same reaction conditions were applied to $\mathbf{1}$, no reaction was observed.

NMR spectroscopy of the resulting product 1 as well as of nido- $\mathrm{SB}_{10} \mathrm{H}_{11}{ }^{-}$was performed at $400 \mathrm{MHz}$. The complete assignments of all resonances to individual cage B-vertices was done also with the aid of GIAO-B3LYP computations and the ${ }^{11} \mathrm{~B}-{ }^{11} \mathrm{~B}$ COSY measurement (see Figure S2). ${ }^{11} \mathrm{~B}$ NMR chemical shifts of nido- $\mathrm{SB}_{10} \mathrm{H}_{11}{ }^{-}$were in agreement with literature values, the latter being based on an alternative procedure to get this nido thiaborane anion. ${ }^{2}$ Chemical shifts are given in ppm to the high frequency (low field) of $\Xi=32.083971 \mathrm{MHz}$ (nominally $\mathrm{F}_{3} \mathrm{~B} . \mathrm{OEt}_{2}$ in $\mathrm{CDCl}_{3}$ ) for ${ }^{11} \mathrm{~B}$ (quoted $\pm 0.5 \mathrm{ppm}$ ), $\Xi=25.144 \mathrm{MHz}$ for ${ }^{13} \mathrm{C}$ (quoted $\pm 0.5 \mathrm{ppm}$ ), and $\Xi=100 \mathrm{MHz}$ for ${ }^{1} \mathrm{H}$ (quoted $\pm 0.05 \mathrm{ppm}$ ); $\Xi$ is defined as in reference and the solvent resonances were used as internal secondary standards.

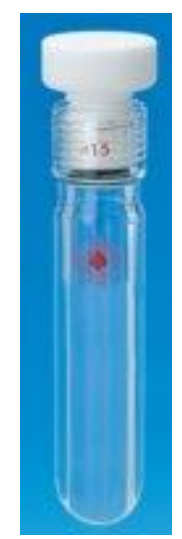

Figure S1. Ace pressure tube, bushing type, front seal, capacity $\sim 38 \mathrm{~mL}$ 


\section{Computational Details}

Magnetic shielding was calculated using the GIAO-B3LYP method incorporated into Gaussian $16^{3}$ utilizing the IGLO-II basis with the MP2/TZVP geometry and frozen-core electrons. Electrostatic potentials were computed at the HF/cc-pVDZ level using Gaussian16 and Molekel4. ${ }^{4}$ programs. It has recently been shown that this basis set size is sufficient for these purposes. ${ }^{5}$ The reaction pathway was searched by means of applying the B3LYP/6$31 \mathrm{G}^{*}$ model chemistry, also taking into account desolvation free energies in methyl iodide by the SMD implicit solvent model. ${ }^{6}$ For the computations of the heats of formation, we used the optimization at the B-P86/def2-TZVP level. Harmonic vibrational calculations were also computed at the B-P86/def2-TZVP level. The energy calculations of the studied molecules and the atoms constituting them were performed at the B3LYP/def2-TZVP level. $\Delta$ Hf298 values were computed by Cuby 4 program package, which is called Turbomole $7.0^{8}$ for harmonic vibrational and energy calculations.

\section{X-ray crystallography}

The X-ray data for obtained for co-crystals of 7,12-I $\mathrm{I}_{2}-2,3,4,5,6,8,9,10,11-\left(\mathrm{CH}_{3}\right)_{9}$-1-closo$\mathrm{SB}_{11}(\mathbf{1})$ and 7,8,12- $\mathrm{I}_{3}-2,3,4,5,6,9,10,11-\left(\mathrm{CH}_{3}\right)_{8}-1$-closo- $\mathrm{SB}_{11}$, grown from a hexane solution by slow evaporation, were collected at $150(2) \mathrm{K}$ with a Bruker D8-Venture diffractometer equipped with a $\mathrm{Mo} / \mathrm{K}_{\alpha}$ radiation; $\lambda=0.71073 \AA$ microfocus $\mathrm{X}$-ray $(\mathrm{I} \mu \mathrm{S})$ source and a Photon CMOS detector. The Oxford Cryosystems cooling device was used for data collection. The frames were integrated with the Bruker SAINT software package using a narrow-frame algorithm. Data were corrected for absorption effects using the Multi-Scan method (SADABS). The data obtained were treated by XT-version 2014/5 and SHELXL-2017/1 software implemented in the APEX3 v2016.5-0 (Bruker AXS) system. ${ }^{9}$ All hydrogen atoms were recalculated into idealized positions (the riding model) and assigned temperature factors $\mathrm{H}_{\text {iso }}(\mathrm{H})=1.2 \mathrm{U}_{\text {eq }}$ (pivot atom) or of $1.5 \mathrm{U}_{\text {eq }}$ (methyl). $\mathrm{H}$ atoms in methyl groups were placed with C-H distances of $0.96 \AA . R_{\text {int }}=\sum\left|F_{\mathrm{o}}{ }^{2}-F_{\mathrm{o} \text {,mean }}{ }^{2}\right| / \sum F_{\mathrm{o}}{ }^{2}, \mathrm{~S}=\left[\sum\left(w\left(F_{\mathrm{o}}^{2}-F_{\mathrm{c}}{ }^{2}\right) /\left(N_{\text {diffrs }}-\right.\right.\right.$ $\left.N_{\text {params }}\right]^{1 / 2}$ for all data, $R(F)=\sum|| F_{\mathrm{o}}|-| F_{\mathrm{c}}|| / \sum\left|F_{\mathrm{o}}\right|$ for the observed data, $w R\left(F^{2}\right)=$ $\left[\sum\left(w\left(F_{\mathrm{o}}^{2}-F_{\mathrm{c}}{ }^{2}\right)^{2}\right) /\left(\sum w\left(F_{\mathrm{o}}{ }^{2}\right)^{2}\right)\right]^{1 / 2}$ for all data. Crystallographic data for structural analysis have been deposited with the Cambridge Crystallographic Data Centre, CCDC no. 2068481 . Copies of this information may be obtained free of charge from The Director, CCDC, 12 Union Road, Cambridge CB2 1EY, UK (fax: +44-1223-336033; email: deposit@ccdc.cam.ac.uk or www: http://www.ccdc.cam.ac.uk).

The crystal data were solved and refined as a two-component twin. Disordered parts were treated by standard methods.

\section{Mass spectrometry}

Mass spectrometry measurements were performed on a Thermo-Finnigan LCQFleet Ion Trap instrument with APCI probe (Atmospheric Pressure Chemical Ionization) in positive enhanced mode using helium (5.0 Messer) as a collision gas in the ion trap. A sample dissolved in acetonitrile (concentration approximately in tens or hundreds of $\mathrm{ng} \mathrm{ml}^{-1}$ ) was introduced to the ion source by infusion of $5 \mu \mathrm{L} / \mathrm{min}$. Conditions used for APCI interface: vaporizer temperature $330{ }^{\circ} \mathrm{C} ; \mathrm{N}_{2}$ (isolated from air in NitroGen N1118LA, Peak Scientific) as a nebulizing sheath gas and auxiliary gas, flow 26 arb. and 5 arb., respectively; discharge 
current $4.2 \mu \mathrm{A}$; capillary temperature $250{ }^{\circ} \mathrm{C}$; capillary voltage $124 \mathrm{~V}$ and mass range from 200 to 1200 . In both cases the positive ions corresponding to the molecular ion were observed with $100 \%$ abundance for the highest peak in the isotopic distribution plot (see Figure S3). Molecular ions $[M]^{+}$were detected for two univalent cations as base peaks in the spectra. The isotopic distribution in the boron plot of obtained peaks was in complete agreement with the calculated spectral pattern. The data are presented for the most abundant mass in the boron distribution plot $(100 \%)$ and for the peak in the boron plot corresponding to the $m / z$ value.

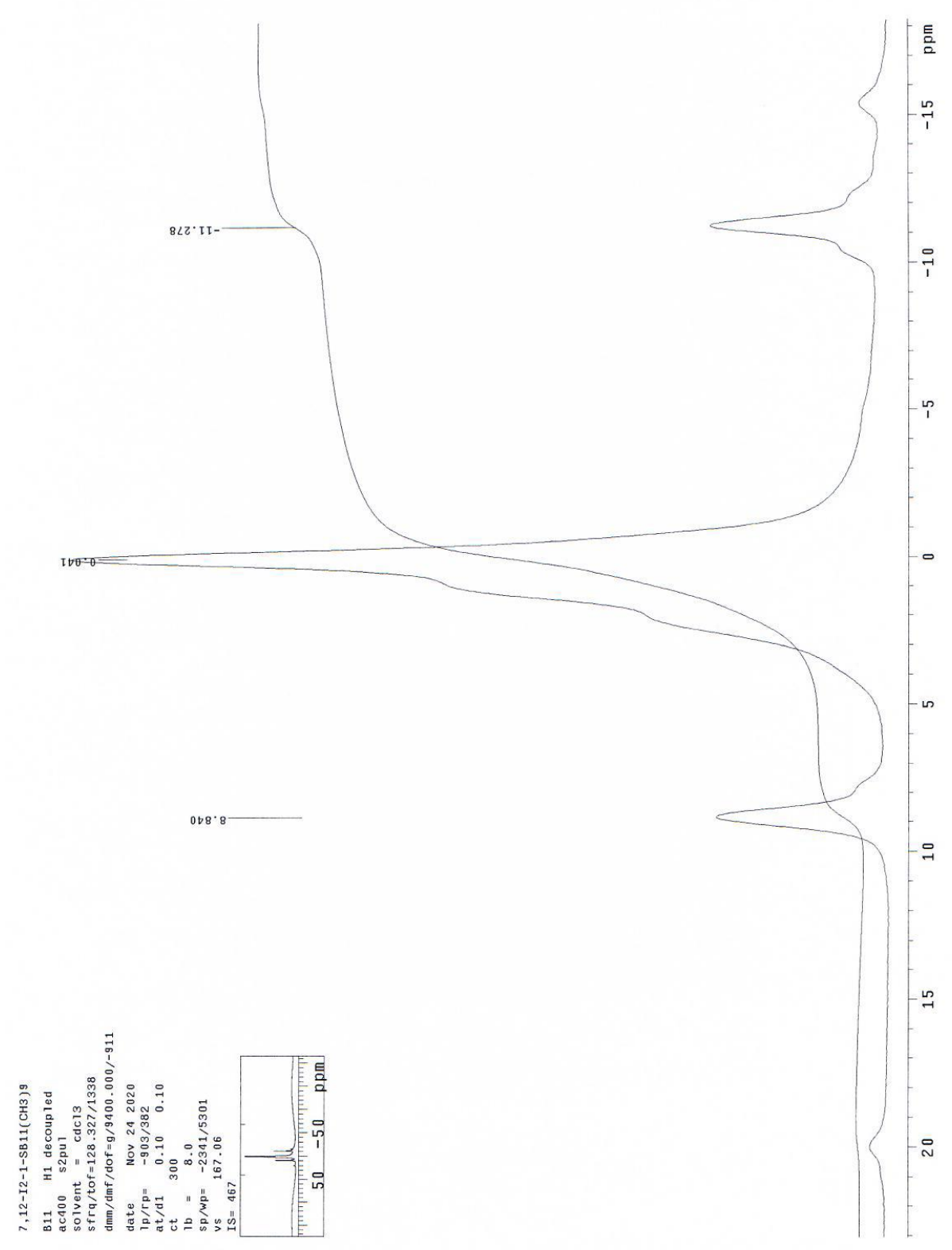

Figure S2. a) ${ }^{1} \mathrm{H}$ decoupled ${ }^{11} \mathrm{~B}$ NMR spectrum of $\mathbf{1}$ 

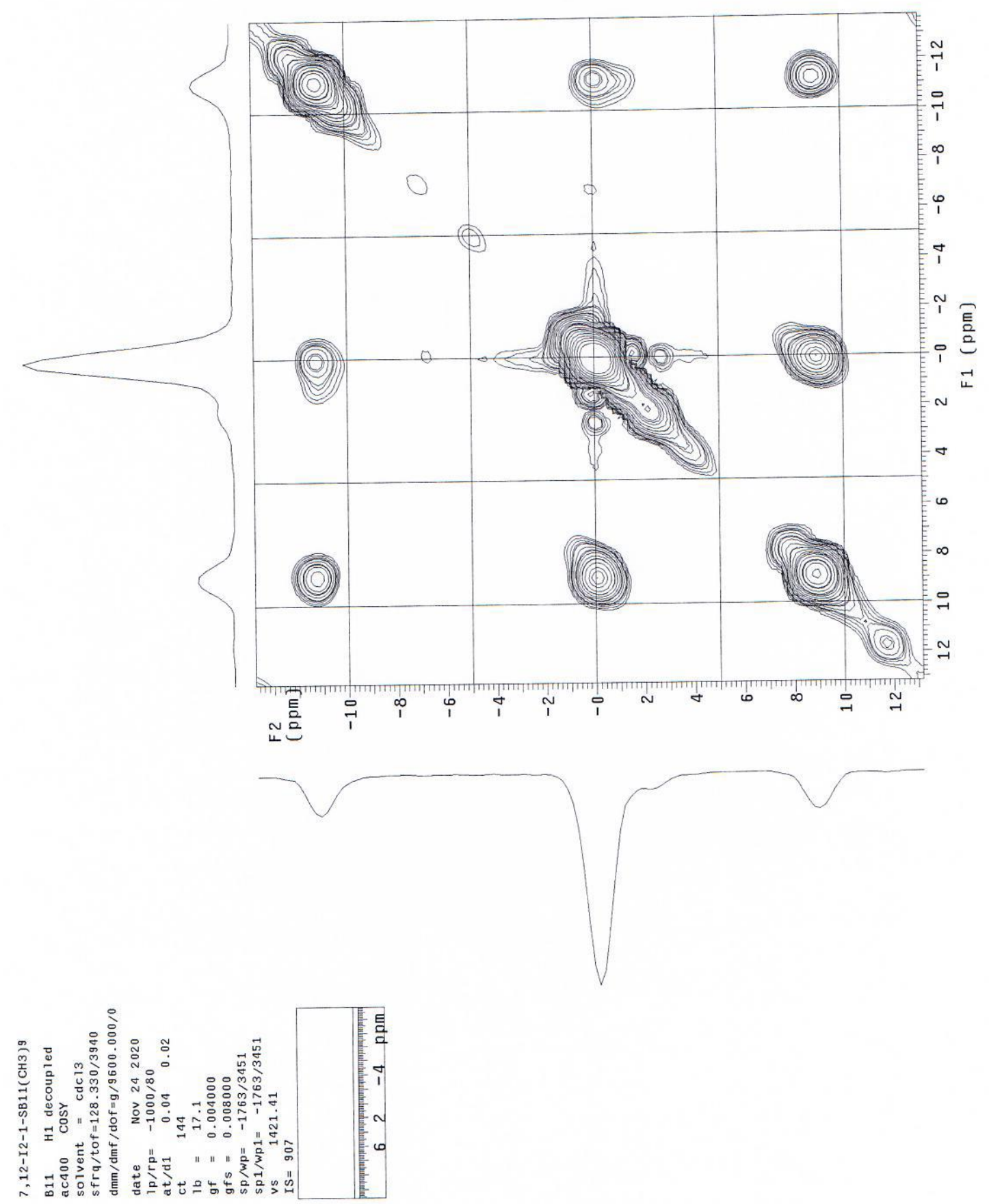

Figure S2. b) ${ }^{11} \mathrm{~B}-{ }^{11} \mathrm{~B}$ COSY spectrum of $\mathbf{1}$ 

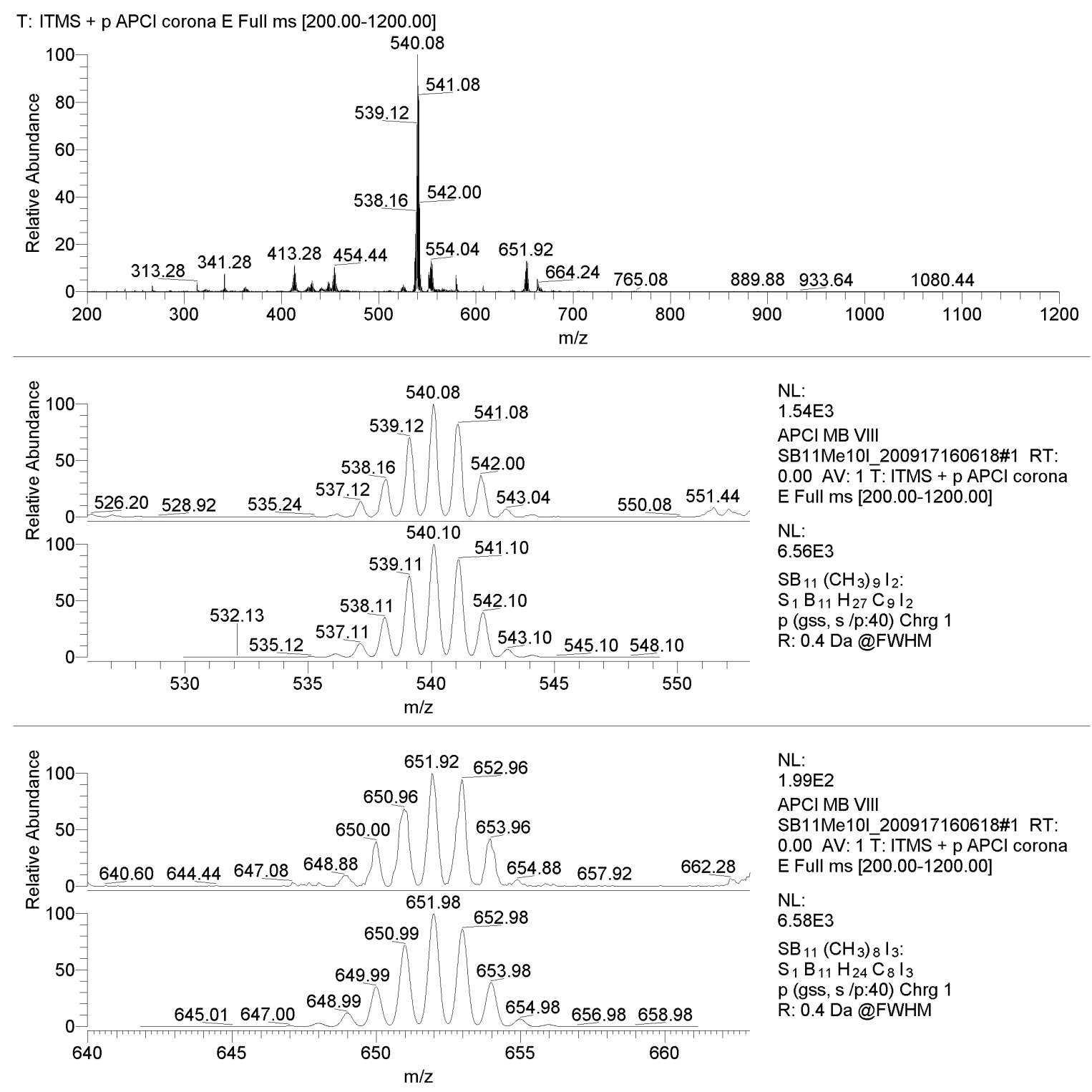

Figure S3. Mass spectra of the sample consisting of 1 and 7,8,12- $\mathrm{I}_{3}-2,3,4,5,6,9,10,11-\left(\mathrm{CH}_{3}\right)_{8}-$ closo-1-SB 11 


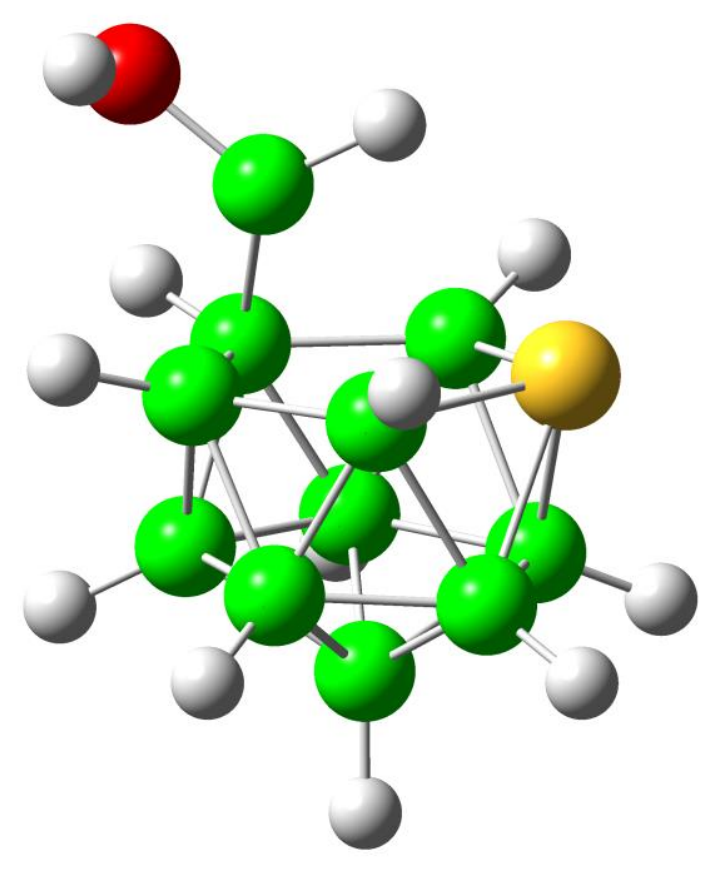

Figure S4. The first TS of the dismantling of closo-1-SB ${ }_{11} \mathrm{H}_{11}$ with $\mathrm{OH}^{-}$

Table S1. Crystalographical details

\begin{tabular}{|c|c|}
\hline \multicolumn{2}{|l|}{ Crystal data } \\
\hline Chemical formula & $0.66\left(\mathrm{C}_{9} \mathrm{H}_{27} \mathrm{~B}_{11} \mathrm{I}_{2} \mathrm{~S}\right) \cdot 0.33\left(\mathrm{C}_{8} \mathrm{H}_{24} \mathrm{~B}_{11} \mathrm{I}_{3} \mathrm{~S}\right)$ \\
\hline$M_{\mathrm{r}}$ & 579.68 \\
\hline Crystal system, space group & Monoclinic, $C c$ \\
\hline Temperature (K) & 150 \\
\hline$a, b, c(\AA)$ & $9.5916(10), 15.9755(15), 14.4947(13)$ \\
\hline$\beta\left(^{\circ}\right)$ & $97.180(3)$ \\
\hline$V\left(\AA^{3}\right)$ & $2203.6(4)$ \\
\hline$Z$ & 4 \\
\hline Radiation type & Mo $K \alpha$ \\
\hline$\mu\left(\mathrm{mm}^{-1}\right)$ & 3.44 \\
\hline Crystal size (mm) & $0.52 \times 0.44 \times 0.28$ \\
\hline
\end{tabular}

Data collection 


\begin{tabular}{|c|c|}
\hline Diffractometer & Bruker D8 - Venture \\
\hline Absorption correction & $\begin{array}{l}\text { Multi-scan } \\
\text { SADABS2016/2 - Bruker AXS area detector scaling and } \\
\text { absorption correction }\end{array}$ \\
\hline$T_{\min }, T_{\max }$ & $0.128,0.247$ \\
\hline $\begin{array}{l}\text { No. of measured, } \\
\text { independent and } \\
\text { observed }[I>2 \sigma(I)] \\
\text { reflections }\end{array}$ & $23795,4191,3274$ \\
\hline$R_{\text {int }}$ & 0.058 \\
\hline$(\sin \theta / \lambda)_{\max }\left(\AA^{-1}\right)$ & 0.611 \\
\hline \multicolumn{2}{|l|}{ Refinement } \\
\hline$R\left[F^{2}>2 \sigma\left(F^{2}\right)\right], w R\left(F^{2}\right), S$ & $0.131,0.373,1.06$ \\
\hline No. of reflections & 4191 \\
\hline No. of parameters & 281 \\
\hline No. of restraints & 632 \\
\hline $\mathrm{H}$-atom treatment & $\begin{array}{l}\text { H-atom parameters constrained } \\
w=1 /\left[\sigma^{2}\left(F_{\mathrm{o}}{ }^{2}\right)+(0.2333 P)^{2}+38.660 P\right] \\
\text { where } P=\left(F_{\mathrm{o}}{ }^{2}+2 F_{\mathrm{c}}{ }^{2}\right) / 3\end{array}$ \\
\hline$\Delta \rho_{\max }, \Delta \rho_{\min }\left(\mathrm{e} \AA^{-3}\right)$ & $2.13,-1.30$ \\
\hline Absolute structure & Refined as an inversion twin. \\
\hline
\end{tabular}

Table S2. Cartesian coordinates of $\mathbf{1}$ as computed at the MP2/TZVP level
$\mathrm{S}$
$2.51185-1.58911 \quad 0.00151$
B $\quad 1.98744 \quad-0.38448-1.54552$
B $\quad 2.76589 \quad 0.42285-0.00255$
B $\quad 1.99033 \quad-0.38171 \quad 1.54428$
B $\quad 0.72882 \quad-1.69308 \quad 0.97026$
B $\quad 0.73243-1.69713-0.96386$
B $\quad 1.44464 \quad 1.16891-0.90586$
B $\quad 1.44662 \quad 1.17179 \quad 0.90196$
B $\quad \begin{array}{lll}0.25211 & -0.05936 & 1.46988\end{array}$
B $\quad-0.45032 \quad-0.82571 \quad 0.00176$
B $\quad 0.24908-0.06528-1.46827$ 


\begin{tabular}{|c|c|c|c|}
\hline B & -0.06332 & 0.90278 & -0.00034 \\
\hline $\mathrm{C}$ & 2.84026 & -0.61947 & -2.85464 \\
\hline $\mathrm{C}$ & 4.28113 & 0.87085 & -0.01354 \\
\hline $\mathrm{C}$ & 2.85002 & -0.60979 & 2.84979 \\
\hline $\mathrm{C}$ & 0.52891 & -3.02389 & 1.79198 \\
\hline $\mathrm{C}$ & 0.53792 & -3.0384 & -1.76982 \\
\hline $\mathrm{C}$ & 1.75043 & 2.48112 & -1.75144 \\
\hline $\mathrm{C}$ & 1.75535 & 2.48826 & 1.73953 \\
\hline $\mathrm{C}$ & -0.53971 & 0.11271 & 2.83579 \\
\hline I & -2.48939 & -1.61859 & -0.00087 \\
\hline $\mathrm{C}$ & -0.55822 & 0.10143 & -2.82598 \\
\hline I & -1.6196 & 2.43598 & -0.00004 \\
\hline $\mathrm{H}$ & -1.6083 & 0.32368 & -2.61966 \\
\hline $\mathrm{H}$ & -0.1573 & 0.92592 & -3.42253 \\
\hline $\mathrm{H}$ & -0.52372 & -0.80241 & $1-3.44049$ \\
\hline $\mathrm{H}$ & -1.45184 & -0.49032 & $2 \quad 2.84083$ \\
\hline $\mathrm{H}$ & 0.06328 & -0.18157 & $7 \quad 3.69971$ \\
\hline $\mathrm{H}$ & -0.83951 & 1.15484 & 4 2.97374 \\
\hline $\mathrm{H}$ & 1.32172 & 2.43246 & 2.742 \\
\hline $\mathrm{H}$ & 2.82959 & 2.66148 & 1.853 \\
\hline $\mathrm{H}$ & 1.32419 & 3.36541 & 1.25022 \\
\hline $\mathrm{H}$ & 0.82859 & 2.89226 & -2.17073 \\
\hline $\mathrm{H}$ & 2.19619 & 3.26078 & -1.12713 \\
\hline $\mathrm{H}$ & 2.43798 & 2.28697 & -2.5798 \\
\hline $\mathrm{H}$ & 1.45498 & -3.3864 & 2.24567 \\
\hline $\mathrm{H}$ & -0.18229 & -2.8348 & 2.60085 \\
\hline $\mathrm{H}$ & 0.11235 & -3.82465 & 1.17713 \\
\hline
\end{tabular}




$\begin{array}{llll}\mathrm{H} & 0.59761 & -3.92335 & -1.13176 \\ \mathrm{H} & -0.45769 & -3.03393 & -2.22079 \\ \mathrm{H} & 1.2676 & -3.14942 & -2.57567 \\ \mathrm{H} & 3.90744 & -0.7891 & 2.63908 \\ \mathrm{H} & 2.7922 & 0.28724 & 3.47294 \\ \mathrm{H} & 2.47941 & -1.44753 & 3.4453 \\ \mathrm{H} & 4.90725 & 0.24603 & -0.65558 \\ \mathrm{H} & 4.34584 & 1.89345 & -0.39627 \\ \mathrm{H} & 4.71879 & 0.86761 & 0.98771 \\ \mathrm{H} & 3.13437 & -1.66244 & -2.99638 \\ \mathrm{H} & 2.24455 & -0.33034 & -3.7251 \\ \mathrm{H} & 3.74897 & -0.01261 & -2.8611\end{array}$

\section{References:}

1. Macháček, J., Plešek, J., Holub, J., Hnyk, D., Všetečka, V., Císařová, I., Kaupp, M. and Štíbr, B. New Route to 1-Thia-closo-dodecaborane(11), closo-1-SB ${ }_{11} \mathrm{H}_{11}$, and its Halogenation Reactions. The Effect of the Halogen on the Dipole Moments and the NMR Spectra and the Importance of Spin-Orbit Coupling for the ${ }^{11}$ B Chemical Shifts. Dalton Trans. 2006, 1024-1029.

2. Serrate, M.T; Ellis, D.; Rosair, G. M.; Welch, A .J. Capping the Thiaborate Anion [nido$\left.\mathrm{SB}_{10} \mathrm{H}_{11}\right]^{-}$. J. Organomet. Chem. 2013, 747, 211-216.

3. Gaussian 16, Revision C.01, Frisch, M. J.; Trucks, G. W.; Schlegel, H. B.; Scuseria, G. E.; Robb, M. A.; Cheeseman, J. R.; Scalmani, G.; Barone, V.; Petersson, G. A.; Nakatsuji, H.; Li, X.; Caricato, M.; Marenich, A. V.; Bloino, J.; Janesko, B. G.; Gomperts, R.; Mennucci, B.; Hratchian, H. P.; Ortiz, J. V.; Izmaylov, A. F.; Sonnenberg, J. L.; Williams-Young, D.; Ding, F.; Lipparini, F.; Egidi, F.; Goings, J.; Peng, B.; Petrone, A.; Henderson, T.;

Ranasinghe, D.; Zakrzewski, V. G.; Gao, J.; Rega, N.; Zheng, G.; Liang, W.; Hada, M.; Ehara, M.; Toyota, K.; Fukuda, R.; Hasegawa, J.; Ishida, M.; Nakajima, T.; Honda, Y.; Kitao, O.; Nakai, H.; Vreven, T.; Throssell, K.; Montgomery, J. A., Jr.; Peralta, J. E.; Ogliaro, F.; Bearpark, M. J.; Heyd, J. J.; Brothers, E. N.; Kudin, K. N.; Staroverov, V. N.; Keith, T. A.; Kobayashi, R.; Normand, J.; Raghavachari, K.; Rendell, A. P.; Burant, J. C.; Iyengar, S. S.; Tomasi, J.; Cossi, M.; Millam, J. M.; Klene, M.; Adamo, C.; Cammi, R.; 
Ochterski, J. W.; Martin, R. L.; Morokuma, K.; Farkas, O.; Foresman, J. B.; Fox, D. J. Gaussian, Inc., Wallingford CT, 2016.

4.a) MOLEKEL 4.3, Flükiger, P.; Lüthi, H. P.; Portmann S.; Weber, J. Swiss Center for Scientific Computing, Manno (Switzerland), 2000; b) S. Portmann, Lüthi. H. P. Chalcogens act as inner and outer heteroatoms in borane cages with possible consequences for $\sigma$-hole interactions. MOLEKEL: CHIMIA 2007, 28, 555.

5. $\quad$ Riley, K. E.; Tran, K.-A.; Lane, P.; Murray J. S.; Politzer, P. Comparative Analysis of Electrostatic Potential Maxima and Minima on Molecular Surfaces, as Determined by Three Methods and a Variety of Basis Sets. J. Comput. Sci. 2016, 17, 273-284.

6. Marenich, A. V.; Cramer, C. J.; Truhlar, D. G. Universal Solvation Model Based on Solute Electron Density and on a Continuum Model of the Solvent Defined by the Bulk Dielectric Constant and Atomic Surface Tensions. J. Phys. Chem. B 2009, 113, 6378-6396.

7. ̌ezáč, J. Cuby: An Integrative Framework for Computational Chemistry. J. Comput. Chem. 2016, 37, 1230-1237.

8. Ahlrichs, R.; Bar, M.; Haser, M.; Horn, H.; Kolmel, C. Electronic Structure Calculations on Workstation Computers: The Program System Turbomole. Chem. Phys. Lett. 1989, 162, $165-169$.

9. Sheldrick, G. M. SHELXT - Integrated Space-Group and Crystal-Structure Determination. Acta Crystallogr., Sect. A.: Found. Adv. 2015, A71, 3-8. 